\title{
Gambaran Kepribadian Dosen-Tetap pada Universitas Swasta Terbaik di Indonesia
}

\author{
Zamralita \\ Fakultas Psikologi, Universitas Tarumanagara \\ Email:zamralita@fpsi.untar.ac.id
}

\begin{abstract}
ABSTRAK
Dosen adalah salah satu komponen utama dalam sistem pendidikan di perguruan tinggi. Tugas utama dosen adalah melaksanakan tridharma Perguruan Tinggi yang terdiri dari pendidikan dan pengajaran, penelitian dan pengabdian pada masyarakat. Terdapat empat kompetensi yang mesti dimiliki dosen, yaitu kompetensi pedagogik, kompetensi profesional, kompetensi sosial dan kompetensi kepribadian. Untuk dapat menjalankan tugas-tugasnya dengan baik, peneliti menduga dosen memiliki karakteristik kepribadian tertentu yang sesuai dengan sifat pekerjaannya, karena profesi dosen berbeda dengan profesi yang lain. Tujuan penelitian untuk memeroleh gambaran kepribadian dosen-tetap. Teori yang digunakan adalah trait kepribadian dari Costa dan McCrae (1992) yang terdiri dari 5 trait yaitu trait openness to experience, trait conscientiousness, trait extraversion, trait agreeableness, dan trait neuroticism. Metode yang digunakan dalam penelitian ini metode kuantitatif. Responden penelitian adalah dosen tetap dari 5 universitas swasta terbaik di Indonesia, yang berjumlah 602 orang. Responden yang berasal dari Universitas 1 (U1) = 158 dosen, Universitas 2 (U2) = 109 dosen, Universitas 3 (U3) = 115 dosen, Universitas $4(U 4)=82$ dosen dan Universitas 5 (U5) $=138$ dosen. Data penelitian diperoleh melalui kuesioner. Analisis data menggunakan anova with in subject. Hasil penelitian menunjukkan dosen-tetap memiliki trait agreeableness yang tinggi $(M=4,29)$, trait conscientiousness yang tinggi $(M=3,90)$, trait extraversion yang tinggi $(M=3,70)$, trait openness to experience yang tinggi $(M=3,66)$ dan trait neuroticism yang rendah $(M=$ 2,24). Kesimpulan dari penelitian ini dosen-tetap memiliki gambaran kepribadian trait agreeableness, trait conscientiousness, trait extraversion, trait openness to experience yang tinggi dan trait neuroticism yang rendah.
\end{abstract}

Kata kunci : trait kepribadian, dosen tetap, universitas swasta

\section{PENDAHULUAN}

Dosen adalah salah satu komponen utama dalam sistem pendidikan di perguruan tinggi. Dosen adalah pendidik profesional dan ilmuwan dengan tugas utama mentransformasikan, mengembangkan, dan menyebarluaskan ilmu pengetahuan, teknologi, dan seni melalui Tridharma Perguruan Tinggi, yakni pendidikan, penelitian, dan pengabdian kepada masyarakat. Agar dapat mengerjakan tugas-tugasnya dengan baik, dosen perlu memiliki kompetensi. Kompetensi merupakan seperangkat pengetahuan, keterampilan, dan perilaku yang harus dimiliki, dihayati, dan dikuasai oleh dosen dalam melaksanakan tugas-tugasnya. Kompetensi yang mesti dimiliki dosen meliputi: (1) kompetensi pedagogik, berkaitan dengan pengelolaan pembelajaran peserta didik; (2) kompetensi profesionalisme, berkaitan dengan penguasaan materi yang komprehensif dan pemahaman terhadap metode dan teknik mengajar yang sesuai; (3) kompetensi sosial, berkaitan dengan kemampuan dosen untuk membina hubungan sosial dengan mahasiswa, kolega, karyawan dan masyarakat untuk menunjang pendidikan; (4) dan kompetensi kepribadian, berkaitan dengan kepribadian yang stabil, dewasa, berwibawa, menjadi teladan dan berakhlak mulia. (Undang-Undang Republik Indonesia Nomor 14 tahun 2005 tentang Guru dan Dosen).

Agar dosen dapat menjalankan tugas-tugasnya yang berkaitan dengan Tridharma Perguruan Tinggi dengan baik, peneliti menduga dosen memiliki karakteristik kepribadian tertentu yang sesuai dengan sifat pekerjaannya (person-job fit) karena profesi dosen tampaknya berbeda dengan profesi yang lain. Hal ini didukung oleh penelitian Seniati (2002) yang menyatakan kesesuaian antara kepribadian karyawan dengan pekerjaannya merupakan salah satu faktor yang memengaruhi komitmen karyawan pada organisasi. Semakin sesuai kepribadian dosen dengan pekerjaannya sebagai dosen maka semakin tinggi komitmen dosen pada universitas. Hasil penelitian Seniati, menunjukkan trait kindness (agreeableness) berpengaruh signifikan terhadap 
komitmen dosen pada universitas sebesar 0,42 $(\mathrm{p}<0,05)$, artinya komitmen dosen ditentukan oleh kesesuaian antara trait kepribadian dosen dengan ciri atau sifat pekerjaan dosen (person-job fit). Hal ini berarti dosen-dosen yang memiliki komitmen tinggi pada universitas adalah dosendosen yang memiliki perhatian dan keinginan untuk menolong orang lain, mau bekerja sama dengan rekan dosen, karyawan, mahasiswa, maupun orang lain di dalam dan di luar fakultas dan universitas; serta selalu ingin berbagi pengetahuan dengan orang lain. (Seniati, 2002).

Hasil penelitian yang lain menjelaskan keterkaitan antara trait kepribadian dengan keterikatan kerja. Langelaan, Bakker, Van Doomen dan Schaufeli (2006) melakukan penelitian pada 572 karyawan, menemukan karyawan yang memiliki keterikatan kerja yang tinggi adalah karyawan yang memiliki trait extraversion tinggi dan trait neuroticism rendah. Sedangkan penelitian Kim, Shin dan Swanger (2009) menemukan hanya trait conscientiousness yang berpengaruh terhadap keterikatan kerja.

Penelitian lain tentang karakteristik kepribadian dilakukan pada sampel yang berbeda dan berkaitan dengan profesi tertentu. Hasil penelitian pada anggota kepolisian di Afrika Selatan mengungkapkan bahwa trait conscientiousness, extraversion dan neuroticism yang berpengaruh terhadap keterikatan kerja.(Mostert \& Rothmann, 2006). Sedangkan penelitian yang dilakukan oleh Zaidi et.al. (2013) pada tenaga pengajar di universitas di Lahore menunjukkan ke empat trait kepribadian berpengaruh terhadap keterikatan kerja, yaitu trait openness to experience, trait conscientiousness, trait extraversion, dan trait agreeableness namun trait neuroticism tidak berpengaruh terhadap keterikatan kerja.

Dari beberapa hasil penelitian yang telah diuraikan di atas menunjukkan kesesuaian antara trait kepribadian dengan pekerjaan dapat berperan sebagai prediktor dari keterikatan kerja dan komitmen organisasi, namun trait kepribadian yang sesuai untuk pekerjaan tertentu dapat berbeda dan bervariasi dengan pekerjaan lainnya, bergantung pada karakteristik pekerjaannya. Dari uraian di atas peneliti menduga bahwa profesi dosen memiliki gambaran kepribadian tertentu yang sesuai dengan sifat/karakteristik pekerjaannya. Adapun tujuan penelitian ini untuk mengetahui gambaran kepribadian pada dosen-tetap (profesi dosen).

\section{TEORI}

\section{Trait kepribadian}

McCrae (2002) merumuskan kepribadian adalah dimensi perbedaan dalam individu untuk menunjukkan pola pikiran, perasaan, dan perilaku yang konsisten. Banyak peneliti sepakat seluruh kepribadian dapat dikategorikan menurut model lima faktor "The Big Five" (Goldberg, 1990). Lima faktor tersebut terdiri dari trait openness to experience, trait conscientiousness, trait extraversion, trait agreeableness dan trait neuroticism.

Trait openness to experience merupakan trait kepribadian yang rentang trait-nya dari imajinatif, sensitif, intelektual, sampai dengan trait yang bersifat tidak sensitif dan konservatif (Greenberg \& Baron, 1997). Trait conscientiousness merupakan trait yang penting pada situasi yang mengutamakan pencapaian prestasi dan secara konsisten berhubungan dengan performansi kerja (Raad, 2000). Trait ini terentang dari trait dengan sifat bertanggung jawab, terorganisasi, memiliki disiplin diri, sampai dengan tidak bertanggung jawab, tidak terorganisasi, dan kurang disiplin diri (Greenberg \& Baron, 1997). Trait extraversion merupakan trait yang paling sering digunakan sebagai prediktor yang baik bagi keberhasilan pekerjaan (Raad, 2000). Trait kepribadian ini terentang dari sifat asertif, mudah bergaul, banyak bicara, sampai dengan sifat tertutup, pendiam, dan pencuriga (Greenberg \& Baron, 1997). Trait extraversion terdiri atas 6 
faset, yaitu warmth, gregariousness, assertiveness, activity, excitement seeking, dan positive emotions (Pervin \& John, 1997). Trait agreeableness merupakan trait yang berhubungan dengan keterampilan interpersonal (Raad, 2000). Trait kepribadian ini terentang dari sifat kooperatif, pemaaf, baik hati, sampai pada sifat pendendam, dan tidak mau bekerja sama (Greenberg \& Baron). Trait Agreeableness terdiri atas 6 faset, yaitu trust, straightforwardness, altruism, compliance, modesty, dan tendermindedness (Pervin \& John, 1997). Trait neuroticism merupakan trait yang terentang dari perasaan tegang, gelisah, murung, negatif, sampai dengan tenang, bergairah, dan positif (Greenberg \& Baron, 1997). Trait kepribadian ini terdiri atas 6 faset, yaitu anxiety, hostility, depression, self-consciousness, impulsiveness, dan vulnerability (Pervin \& John, 1997).

\section{METODE PENELITIAN}

Metode penelitian ini adalah penelitian kuantitatif. Karakteristik responden dalam penelitian ini adalah dosen tetap yang berasal dari lima universitas swasta terbaik di Indonesia berdasarkan survey yang dilakukan oleh Buku Tempo (2010). Adapun dasar penilaian yang digunakan Buku Tempo adalah dosen yang mengajar berkualitas, memiliki reputasi sebagai perguruan tinggi swasta yang bagus, lulusan tidak kesulitan mendapatkan pekerjaan, biaya kuliah terjangkau, sarana belajar mengajar memadai, perguruan tinggi swasta tersebut memiliki ijin dari Dirjen Pendidikan Tinggi, Status akreditasi program studi yang dipilih, dan jumlah dosen dan mahasiswa seimbang.(Tempo, 2010). Teknik sampling yang digunakan purposive (non probability sampling).

Variabel dalam penelitian ini adalah Kepribadian. Data diperoleh dengan menyebarkan kuesioner pada dosen-tetap yang berusia 25-75 tahun, laki-laki dan perempuan dengan masa kerja minimal 3 tahun. Kuesioner yang digunakan adalah tes lima dimensi yang dibuat oleh Sumintardja (2009). Tes lima dimensi memiliki nilai reliabilitas yang baik untuk setiap dimensinya. Koefisien reliabilitas internal dari dimensi trait openness to experience $=0,784$, dimensi trait conscientiousness $=0,810$, dimensi trait extraversion $=0,787$, dan dimensi trait agreeableness $=0,749$ dan dimensi trait neuroticism $=0,786$. Selanjutnya gambaran responden yang terdiri dari lima universitas yaitu universitas 1 disingkat menjadi U1, universitas 2 disingkat U2, universitas 3 disingkat menjadi U3, universitas 4 disingkat menjadi U4 , universitas 5 disingkat menjadi U5, yang dapat dilihat pada Tabel 1.

Tabel 1. Gambaran responden berdasarkan universitas

\begin{tabular}{llcc}
\hline No & Kode Universitas & Jumlah & Persentase \\
\hline 1. & Universitas 1 (U1) & 158 & $26 \%$ \\
2. & Universitas 2 (U2) & 109 & $18 \%$ \\
3. & Universitas 3 (U3) & 115 & $19 \%$ \\
4. & Universitas 4 (U4) & 82 & $14 \%$ \\
5. & Universitas 5 (U5) & 138 & $23 \%$ \\
& Total & 602 & $100 \%$ \\
\hline
\end{tabular}

\section{HASIL DAN PEMBAHASAN \\ Gambaran kepribadian}

Penelitian ini dilakukan pada lima universitas terbaik di Indonesia. Untuk memperjelas gambaran kepribadian akan dibahas gambaran kepribadian dosen tetap dari setiap universitas (U1, U2, U3, U4 dan U5). Kategori yang akan digunakan adalah sebagai berikut: Rendah = skor rata-rata 1-2,49; Rata-rata $($ Sedang) $=$ skor rata-rata 2,5-3,5; dan Tinggi $=$ skor rata-rata 3,515,00 . 
Berikut ini akan diuraikan gambaran kepribadian dosen tetap pada Universitas 1 (U1), memiliki trait agreeableness yang tinggi $(\mathrm{M}=4,38)$, trait conscientiousness yang tinggi $(\mathrm{M}=4,04)$, trait extraversion yang tinggi $(M=3,78)$, trait openness to experience yang tinggi $(M=3,56)$ dan trait neuroticism yang rendah $(\mathrm{M}=2,16)$ yang dapat dilihat pada Tabel 2.

Tabel 2. Gambaran trait kepribadian dosen tetap U1

\begin{tabular}{lcc}
\hline Trait Kepribadian & Mean (skala 1-5) & Kategori \\
\hline Agreeableness & 4,38 & Tinggi \\
Conscientiousness & 4,04 & Tinggi \\
Extraversion & 3,78 & Tinggi \\
Opennes to experience & 3,56 & Tinggi \\
Neuroticism & 2,16 & Rendah \\
\hline
\end{tabular}

Gambaran kepribadian dosen-tetap Universitas 2 (U2), memiliki trait agreeableness yang tinggi $(\mathrm{M}=4,16)$, trait conscientiousness yang tinggi $(\mathrm{M}=3,81)$, trait openness to experience yang tinggi $(M=3,64)$, trait extraversion yang tinggi $(M=3,62)$ dan trait neuroticism yang rendah $(M=$ $2,24)$ yang dapat dilihat pada Tabel 3.

Tabel 3. Gambaran trait kepribadian dosen tetap U2

\begin{tabular}{lcc}
\hline Trait Kepribadian & Mean (skala 1-5) & Kategori \\
\hline Agreeableness & 4,16 & Tinggi \\
Conscientiousness & 3,81 & Tinggi \\
Openness to experience & 3,64 & Tinggi \\
Extraversion & 3,62 & Tinggi \\
Neuroticism & 2,24 & Rendah \\
\hline
\end{tabular}

Gambaran kepribadian dosen-tetap Universitas 3 (U3), memiliki trait agreeableness yang tinggi $(\mathrm{M}=4,33)$, trait conscientiousness yang tinggi $(\mathrm{M}=3,84)$, trait extraversion yang tinggi $(\mathrm{M}=3,67)$, trait openness to experience yang tinggi $(\mathrm{M}=3,64)$, dan trait neuroticism yang rendah $(\mathrm{M}=2,22)$ yang dapat dilihat pada Tabel 4 .

Tabel 4. Gambaran trait kepribadian dosen tetap U3

\begin{tabular}{lcc}
\hline Trait Kepribadian & Mean (skala 1-5) & Kategori \\
\hline Agreeableness & 4,33 & Tinggi \\
Conscientiousness & 3,84 & Tinggi \\
Extraversion & 3,67 & Tinggi \\
Openness to experience & 3,64 & Tinggi \\
Neuroticism & 2,22 & Rendah \\
\hline
\end{tabular}

Gambaran kepribadian dosen-tetap Universitas 4 (U4), memiliki trait agreeableness yang tinggi $(\mathrm{M}=4,22)$, trait conscientiousness yang tinggi $(\mathrm{M}=3,90)$, trait openness to experience yang tinggi $(\mathrm{M}=3,65)$, trait extraversion yang tinggi $(\mathrm{M}=3,62)$ dan trait neuroticism yang rendah $(\mathrm{M}=2,39)$ yang dapat dilihat pada Tabel 5 .

Gambaran kepribadian dosen-tetap Universitas 5 (U5), memiliki trait agreeableness yang tinggi $(\mathrm{M}=4,30)$, trait conscientiousness yang tinggi $(\mathrm{M}=3,88)$, trait extraversion yang tinggi $(\mathrm{M}=3,74)$, trait openness to experience yang tinggi $(\mathrm{M}=3,73)$, dan trait neuroticism yang rendah $(\mathrm{M}=2,28)$ yang dapat dilihat pada Tabel 6 . 
Tabel 5. Gambaran trait kepribadian dosen tetap U4

\begin{tabular}{lcc}
\hline Trait Kepribadian & Mean (skala 1-5) & Kategori \\
\hline Agreeableness & 4,22 & Tinggi \\
Conscientiousness & 3,90 & Tinggi \\
Openness to experience & 3,65 & Tinggi \\
Extraversion & 3,62 & Tinggi \\
Neuroticism & 2,39 & Rendah \\
\hline
\end{tabular}

Tabel 6. Gambaran trait kepribadian dosen tetap U5

\begin{tabular}{lcc}
\hline Trait Kepribadian & Mean (skala 1-5) & Kategori \\
\hline Agreeableness & 4,30 & Tinggi \\
Conscientiousness & 3,88 & Tinggi \\
Extraversion & 3,74 & Tinggi \\
Openness to experience & 3,73 & Tinggi \\
Neuroticism & 2,28 & Rendah \\
\hline
\end{tabular}

Gambaran kepribadian dosen-tetap dari seluruh universitas (U1-U5) menunjukkan seluruh dosen memiliki gambaran kepribadian tertentu yang terdiri dari trait agreeableness yang tinggi $(\mathrm{M}=4,29)$, trait conscientiousness yang tinggi $(\mathrm{M}=3,90)$, trait extraversion yang tinggi $(\mathrm{M}=$ $3,70)$, trait openness to experience yang tinggi $(\mathrm{M}=3,66)$ dan trait neuroticism yang rendah $(\mathrm{M}$ $=2,24)$, yang dapat dilihat pada Tabel 7 .

Tabel 7. Gambaran trait kepribadian dosen tetap dari seluruh universitas

\begin{tabular}{lcc}
\hline Trait Kepribadian & Mean (skala 1-5) & Kategori \\
\hline Agreeableness & 4,29 & Tinggi \\
Conscientiousness & 3,90 & Tinggi \\
Extraversion & 3,70 & Tinggi \\
Openness to experience & 3,66 & Tinggi \\
Neuroticism & 2,24 & Rendah \\
\hline
\end{tabular}

Jika dicermati data dari setiap universitas dimulai dari U1 sampai U5, terlihat bahwa dosen memiliki gambaran kepribadian yang relatif sama yaitu trait agreeableness tinggi, trait conscientiousness tinggi, trait extraversion tinggi, trait openness to experience tinggi dan trait neuroticism yang rendah.

Dari penelitian ini ditemukan trait agreeableness yang paling tinggi dibandingkan trait lain. Trait agreeableness biasanya dikaitkan dengan keterampilan interpersonal. Dosen tetap dari universitas terbaik di Indonesia yang memiliki skor tinggi pada trait agreeableness ini akan tampak dalam perilakunya ramah, baik hati, suka bekerja sama, memiliki perhatian dan keinginan untuk menolong orang lain, baik mahasiswa, rekan dosen lain, karyawan maupun orang lain. Trait ini tampaknya dapat mendukung kompetensi sosial dan kompetensi kepribadian yang seyogianya dimiliki oleh dosen. Artinya jika dosen memiliki trait agreeableness yang tinggi akan mendorong pembentukan dan peningkatan kompetensi sosial dan kompetensi kepribadian yang akhirnya dapat memberikan kontribusi terhadap penyelesaian tugas-tugas dosen.

Trait yang memiliki skor tinggi ke dua adalah trait conscientiousness. Dosen yang memiliki skor tinggi pada trait conscientiousness memiliki ciri-ciri kompeten, memiliki perencanaan dalam mengerjakan tugas, mampu mengatur diri, mampu mengorganisir kegiatan yang sangat 
bervariasi, tekun dan disiplin. Trait ini akan memengaruhi cara kerjanya ketika melakukan tugas-tugasnya sebagai dosen khususnya dalam mengerjakan tugas-tugas yang terkait dengan Tridharma Perguruan Tinggi yang meliputi kegiatan pendidikan dan pengajaran, penelitian dan pengabdian pada masyarakat. Selain itu dosen yang memiliki trait conscientiousness tinggi akan memperlihatkan perilaku disiplin, memiliki dorongan untuk bekerja keras, memiliki ketekunan, bertanggung jawab terhadap penyelesaian tugas, sifat-sifat ini sangat membantu untuk meningkatkan kompetensi pedagogik dan kompetensi profesional yang seyogianya dimiliki oleh dosen. Dosen yang memiliki trait conscientiousness tinggi akan mampu menyesuaikan diri dengan pekerjaan dosen yang memiliki otonomi tinggi dalam menyelesaikan pekerjaannya. Dosen akan dapat mengatur waktunya dengan baik untuk mengajar, membimbing dan menguji skripsi, tesis dan disertasi mahasiswa. Selain itu dosen juga perlu membagi waktu antara tugas pendidikan dan pengajaran, penelitian dan pengabdian pada masyarakat.

Selain itu dosen juga memiliki trait extraversion yang tinggi, yang tampak dari perilaku ramah pada orang lain, mudah membina relasi dengan orang lain, senang bergaul, bersemangat dan optimis. Trait ini akan mendukung kompetensi sosial yang perlu dimiliki dosen. Disamping itu dosen juga memiliki trait openness to experience yang tinggi akan tampak melalui rasa ingin tahu yang besar dan terbuka terhadap ide/gagasan yang baru. Dosen yang memiliki trait openness to experience yang tinggi akan memiliki gairah untuk mengikuti perkembangan ilmu dari berbagai sumber, mengadakan penelitian untuk memperdalam suatu teori atau menguji teori dan bersedia menerima masukan dari orang lain. Trait ini dapat mendukung kompetensi pedagogik yang seharusnya dimiliki dosen.

Trait kepribadian yang berbeda dari ke empat trait kepribadian lainnya adalah trait neuroticism. Kalau ke empat trait kepribadian lainnya akan dinilai positif jika berada dalam kategori tinggi namun trait neuroticism akan dinilai positif jika berada dalam kategori rendah. Dosen yang memiliki trait neuroticism yang rendah akan memiliki emosi yang stabil, mempunyai level toleransi terhadap stres yang tinggi, berusaha mengatasi permasalahan dan tidak menghindari permasalahan. Trait neuroticism yang rendah, sama artinya dengan emotional stability, trait ini dapat mendukung kompetensi kepribadian yang perlu dimiliki dosen. Trait emotional stability diperlukan bagi profesi dosen karena dosen merupakan salah satu profesi yang rentan terhadap stres dan burn out. Kondisi burn out umumnya dialami oleh profesi yang banyak berhubungan dengan orang lain seperti dosen, yang biasanya mengalami banyak tuntutan dari mahasiswa, rekan dosen, fakultas dan universitas. Dosen yang memiliki trait neuroticism yang rendah diharapkan akan memiliki emosi yang stabil dan mampu menyelesaikan permasalahan yang dihadapi yang terkait dengan mahasiswa, dosen lain, pengelola fakultas atau lingkungan luar.

\section{KESIMPULAN DAN SARAN}

\section{Kesimpulan}

Dari lima universitas yang menjadi responden penelitian, setiap universitas menunjukkan hasil yang relatif sama yaitu dosen memiliki trait agreeableness tinggi, trait conscientiousness tinggi, trait extraversion tinggi, trait openness to experience tinggi dan neuroticism yang rendah. Hasil penelitian ini mengungkapkan profesi dosen memiliki gambaran kepribadian tertentu, yang mungkin berbeda dengan profesi yang lain.

\section{Saran-saran}

Kesesuaian antara kepribadian dan karakteristik pekerjaan merupakan hal yang penting. Hasil penelitian ini dapat digunakan sebagai rekomendasi untuk menggunakan tes psikologi dalam 
proses seleksi, khususnya tes kepribadian agar dapat diperoleh calon dosen tetap dengan gambaran kepribadian tertentu yang sesuai dengan karakteristik pekerjaan dosen.

\section{Ucapan Terima Kasih}

Peneliti mengucapkan terima kasih pada Pimpinan Universitas dan Fakultas yang telah mengijinkan peneliti melakukan pengambilan data penelitian. Secara khusus ucapan terima kasih dan penghargaan juga peneliti sampaikan untuk seluruh dosen tetap yang telah berpartisipasi dalam penelitian ini

\section{REFERENSI}

Costa, P.T. dan R.R. McCrae (1992). Revised NEO Personality Inventory (NEO PI-R) and Neo Five Factor Inventory (NEO-FFI). Odessa, FL: Psychological Assessment Resource, Inc.

Goldberg, L.R. (1990). An alternative description of personality: The big five factor structure. Journal of personality and social psychology, 59, 1216-1229.

Greenberg, J., Baron, R. A. (1997). Behavior in organizations: understanding and managing the human side of work ( $6^{\text {th }}$ ed.). NJ: Prentice-Hall

Kim, H.J., Shin, K.H., \& Swanger, N. (2009). Burnout and engagement: A comparative analysis using The Big Five personality dimensions. International Journal of Hospitality Management, 28, 96-104.

Langelaan, S., Bakker, A.B., van Doornen, L.J.P., \& Schaufeli, W.B. (2006). Burnout and work engagement: Do individual differences make a difference?. Personality and Individual Differences, 40, 521-532.

McCrae, R.R. (2002). Cross-cultural research on the five-factor model of personality.

Mostert, K., \& Rothmann, S. (2006). Work related well - being in the South African police service. Journal of Criminal Justice, 94, 1452-1465.

Pervin, L. A., John, O. P. (1997). Personality: theory and research $\left(7^{\text {th }}\right.$ ed.). NY: John Wiley \& Sons.

Raad, B. D. (2000). The big five personality factors: the psycholexical approach to personality. Göttingen: Hogrefe \& Huber Publishers.

Seniati, A.N.L. (2002). Pengaruh masa kerja, trait kepribadian, kepuasan kerja, dan iklim psikologis terhadap komitmen dosen pada Universitas Indonesia. Disertasi tidak dipublikasikan, Fakultas Psikologi Universitas Indonesia, Depok.

Sumintardja, E.N., (2009). Tes Lima Dimensi. Tidak dipublikasikan.

Tim Tempo (2010). Panduan memilih Perguruan Tinggi. Gramedia, Jakarta.

Undang-Undang Republik Indonesia Nomor 14 tahun 2005 tentang Guru dan Dosen.

Zaidi, N.R., Wajid, R.A., Zaidi, F.B., Zaidi, G.B., \& Zaidi, M.T. (2013). The big five personality traits and their relationship with work engagement emong public sector university teachers of Lahore. African Journal of Business Mangement, 7(15), 1344-1353. 